\title{
Mathematical Literacy teachers' engagement with contextualised income tax calculations
}

\author{
Authors: \\ Sarah Bansilal ${ }^{1}$ \\ Thokozani W. Mkhwanazi ${ }^{1}$ \\ Affiliations: \\ ${ }^{1}$ Department of Mathematics \\ Education, School of \\ Education, University of \\ KwaZulu-Natal, South Africa \\ Correspondence to: \\ Sarah Bansilal \\ Email: \\ bansilals@ukzn.ac.za \\ Postal address: \\ 8 Zeeman Place, Malvern \\ 4093, South Africa \\ Dates: \\ Received: 20 Sept. 2014 \\ Accepted: 17 Nov. 2014 \\ Published: 12 Dec. 2014 \\ How to cite this article: \\ Bansilal, S., \& Mkhwanazi, \\ T.W. (2014). Mathematical \\ Literacy teachers' \\ engagement with \\ contextualised income tax \\ calculations. Pythagoras, \\ 35(2), Art. \#246, 10 pages. \\ http://dx.doi.org/10.4102/ \\ pythagoras.v35i2.246

\section{Copyright:} \\ C 2014. The Authors. \\ Licensee: AOSIS \\ OpenJournals. This \\ work is licensed under \\ the Creative Commons \\ Attribution License.
}

\section{Read online:}

Scan this $Q R$ code with your smart phone or mobile device to read online.
This study focuses on teachers' engagement with tasks based on the income tax tables issued by the South African tax authorities. The participants in the study are a group of 37 teachers who were enrolled in an in-service programme for Mathematical Literacy teachers. The purpose of the study is to explore the teachers' interpretation and use of the rule used to calculate income tax. Data were generated from written responses of the teachers to three tasks, as well as follow-up interviews with eight of the participants. The findings indicate that some teachers $(8 \%)$ did not recognise any of the demands inherent in the income tax rule that they teach to their learners. Most teachers (54\%) were in the novice category, showing that they met some of the demands but need some help in carrying out the rule fluently. A further $32 \%$ were able to use the rule to work out the tax given various input incomes, but could not use the rule to find the input income when given the tax output, because they did not have the necessary algebraic skill.

\section{Introduction}

The introduction of Mathematical Literacy (ML) in South Africa in 2006 led to exciting opportunities for mathematics literacy educators in terms of developing new classroom materials, assessment activities, as well as research studies that focus on real-life contexts. ML as a subject includes 'elementary mathematical concepts and skills' (commonly understood as those mathematics domains that are studied in the GET phase) (Department of Basic Education, 2011, p. 8). It also comprises a number of contextual domains that are deemed to be useful in attaining the lifepreparation goals of ML, which seek to develop self-managing persons, contributing workers and participating citizens (Department of Basic Education, 2011, p. 8).

The importance of ML lies in this life-preparation orientation, a fact that seems to be forgotten by some vocal critics, such as Jansen (2011), who view ML as a watered-down version of mathematics. The subject ML aims to develop skills that will enable learners to participate in (and not be excluded from) situations that use numerically based arguments. This study set around the theme of income tax fits in very well with the life-preparation orientation of ML and can therefore illustrate some of the value offered by the subject. The purpose of this study is to explore the varying levels of engagement with a contextual rule located in the income tax domain. By looking at what we call a contextual rule (somewhat different from the usual procedures and concepts encountered in school mathematics), we hope to contribute to a more nuanced understanding of what conceptual understanding in ML could be, and how this could relate with conceptual understanding in mathematics. An improved understanding of varying levels of understanding of contextual rules will also help teachers and teacher educators understand 'what makes the learning of specific topics easy or difficult' (Shulman, 1986, p. 9), thereby contributing to the development of our (ML educators') pedagogical content knowledge (PCK) of ML. In this study we analyse teachers' written responses to three ML tasks based on income tax calculations. The research question that underpins this study is: How do ML teachers engage with the income tax contextual rule?

\section{Literature review}

The introduction of the ML in South African schools has opened up spaces for research in many areas, including studies about learners' perceptions of and attitudes towards the subject, teachers' perceptions of the subject, teaching practices of ML teachers, professional development for ML teachers, conceptual understanding of mathematics concepts embedded in ML as well as conceptual understanding of ML concepts. In this study, the teachers can be considered as learners in an in-service programme so we first survey some literature about learners' understanding of ML, before moving to studies conducted on teachers. Venkat and Graven (2008) examined learners' perceptions of ML in Grade 10 in an inner-city Johannesburg school and were able to show that highly negative experiences of learning Mathematics in Grade 9 had been transformed 
into highly positive perceptions of learning ML in Grade 10. Through information gathered from questionnaires and interviews with selected learners, Venkat and Graven were able to attribute this positive perception of ML to the opening up of learning spaces within the classroom in terms of what learners described as shifts in the nature of classroom task and in the nature of interaction in ML. In terms of the nature of classroom tasks, learners viewed contextual tasks as more accessible, practical, 'visualise-able' and providing openings for communication, participation and sense making inside and outside school. Venkat (2010) also looked at how learners' mathematical proficiency improved whilst engaging in ML activities. She wrote that some strands that are usually under-represented in mainstream mathematics classrooms such as 'strategic competence, adaptive reasoning and the development of a productive disposition feature strongly in ML lessons' (Venkat, 2010, p. 66). This statement highlights some differences between a Mathematics and an ML classroom.

Another key difference between a Mathematics and an ML classroom is the role of the context. With the former, contexts are often used to illuminate the mathematics or to illustrate how the mathematics can emerge (for example drawing upon a temperature gauge to motivate for addition and subtraction rules of integers). With the latter the focus is on the interpretation and exploration of the context. Studies based on the intricacies of engaging with ML contextualised tasks can help us understand some of the complexities involved. Bansilal and Debba (2012) carried out a study with a class of 73 Grade 12 ML learners, which explored learners' recognition, interpretation and use of various contextual attributes. The context in the study (FIFA World Cup) was understood in terms of attributes that provide the resources for the interpretation of the event. In general, learners found it easier to work with calculations using the contextual rules than to engage in reasoning about the rules. A common tendency of relying on their everyday reasoning instead of contextual reasoning was identified. It was also found that some learners did not understand some of the contextual language, which limited their responses to the assessment items. Vale (2012) carried out a study with 43 ML learners that was also based on an assessment designed around the FIFA World Cup. Although the context was the same in the two studies (Bansilal \& Debba, 2012; Vale, 2012), the focal events (the focus of the tasks) differed. Whereas the setting for the former study (Bansilal \& Debba, 2012) was the soccer scoring formats, in the case of Vale's (2012) study, the focal event was the pricing structure of the tickets for the matches. Vale found that all the participants lost marks due to a failure to decode the contextual language. There have been many studies about the professional development of ML teachers and their classroom practice (Botha, 2011; Hechter, 2011; Nel, 2012; Pillay, 2006), and fewer about ML teachers' knowledge and engagement with specific ML concepts. Bansilal (2011) carried out a study on teachers' engagement with the concept of inflation, which used a process-object framework to understand the teachers' varying levels of engagement with the inflation rate signifier. Another study by Bansilal, Mkhwanazi and Mahlabela (2012) focused on 108 teachers' interpretation and use of the transfer duty rule, which is used to calculate the transfer duty payable when somebody buys a house. It was found that whilst most of the group (89\%) was able to carry out the routine calculations, only half the group were able to carry out more complex calculations.

\section{Theoretical framework}

Greeno (1991) describes a conceptual domain in mathematics as an environment with resources at various places in the domain. Knowing the mathematics domain lies in the ability to recognise, find and use those resources productively. Our perspective is that ML is a subject that entails the use of mathematical tools and resources together with those from the contextual domain, in order to solve problems.

We first clarify our meaning of context. Gilbert (2006, p. 960) explains that the Latin form contextus expresses 'coherence, connection and/or relationship'. Gilbert states that the function of the context is 'to describe such circumstances that give meaning to words, phrases, and sentences'. Duranti and Goodwin (1992, p. 3) use the term 'focal event' to identify the phenomenon being contextualised:

When the issue of context is raised it is typically argued that the focal event cannot be properly understood, interpreted appropriately, or described in a relevant fashion, unless one looks beyond the event itself to other phenomena (for example cultural setting, speech situation, shared background assumptions) within which the event is embedded, or alternatively that features of the talk itself invoke particular background assumptions relevant to the organisation of subsequent interaction. (Duranti \& Goodwin, 1992, p. 3)

The context thus involves two entities: a focal event and a field of action within which the event is being embedded. In this study the focal event is the calculation of the income tax. Duranti and Goodwin (1992, pp. 6-8) identify four 'attributes' of educational contexts, which are elaborated below in terms of how they relate to this study:

1. Contextual setting: This refers to the social and spatial setting within which the interactions take place. In this study the contextual setting is that of the income tax payable by South African taxpayers.

2. Behavioural environment: This refers to the framing that establishes 'the preconditions for coordinated social action by enabling participants' (p. 7) to predict what is about to happen. In this study the behavioural environment is the formative assessment within which the contextual task was presented.

3. Use of language: This refers to the ways 'in which talk itself invokes context and provides context for other talk' (p. 7). In this study we use the phrase contextual language to refer to words or phrases that hold a particular meaning within the context. For example, '200 free kilometres per

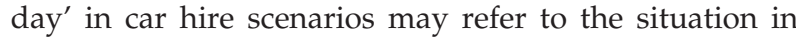


which the contract allows you to drive up to $200 \mathrm{~km}$ a day without incurring additional charges and 'win by a margin of 2 or more' in the context of soccer matches refers to the situation where the difference between the goals scored by the winning and the losing teams is 2 or more than 2.

4. Extra-situational background knowledge: This refers to the background knowledge that extends beyond the immediate setting, which is necessary for an appropriate understanding of the focal event. In this study we define two aspects of this contextual background knowledge that are pertinent to this study. (See Bansilal, 2013, as well as Bansilal \& Debba, 2012, for other examples of contextual attributes.) Firstly contextual signifiers are the signifiers used in the context to convey specific information and which have a meaning that is bounded by the parameters of the context. For example, if the reported infant mortality rate in South Africa in 2012 was 42.67, this figure represents the fact that the number of infant deaths during the first year of life per thousand live births' (KwaZulu-Natal Department of Education, 2009) was 42.67. Secondly contextual rules are bound to the context and need to be interpreted by the learner. In this study the rule used to calculate the income tax payable on a certain income is an example of a contextual rule. To summarise, the focal event is the calculation of the income tax and the contextual attributes are the tools and resources used to throw light upon this focal event.

\section{Methodology}

This study is qualitative in nature, taking on an interpretative, naturalistic approach in line with Denzin and Lincoln's (2008) description that 'qualitative researchers study things in their natural settings, attempting to make sense of, or interpret, phenomena in terms of the meaning people bring to them' (p. 4). The purpose of this study was to explore the levels of engagement of ML teachers with the income tax contextual rule.

The instruments for data collection were a set of three tasks that were specially designed for both assessment and research purposes and were administered as part of a routine class assessment to the participants who were enrolled for the Advanced Certificate in Education: Mathematical Literacy (ACE ML). The ACE programme under discussion in this article was made up of eight modules consisting of six ML-specific modules and two generic education modules. The research study was located in one of the ML-specific modules which focused on numbers and operations in real-life contexts. There were 40 teachers who completed the assessment task, but 3 did not respond to the tasks on the income tax rule; hence, there were 37 participants whose responses were analysed. From the sample of 37 teachers, 8 participants consented to our request for an interview. The purpose of the semi-structured interviews was to find out more about their reasoning and reflections that influenced their written responses. Thereafter, the process of analysis was undertaken by the two researchers (authors). The analytic framework was drawn up based on the contextual attributes theory and this informed the coding of the teachers' responses.

We now present a discussion of the three research items; this is then followed by details of the categories comprising the analytic framework.

\section{Research items}

In this study we explore teachers' engagement with the contextual rule used to calculate the income tax. The calculation of income tax is an important ML topic that can contribute to the attainment of the life preparation and citizenship goals of ML, by contributing to an understanding of how income tax is calculated. The three tasks under scrutiny involve the income tax rule used to calculate the amount payable by any employed person. The costs that are payable, are described in different levels and can be modelled by a piecewise function, where each piece is defined by a separate rule or formula over a specified domain. Luthuli (2000) wrote an account of real-life applications of such piecewise functions by describing how one could use integer-valued functions to derive formulae to describe the real-life context or problem. An example of a piecewise function that models the income tax rule (for people under 65) for the first task (as described in Figure 1) can be represented symbolically by $f(x)$ :

$f(x)= \begin{cases}0,18 x-8280 & \text { if } 46000 \leq x \leq 122000 \\ 0,25 x-16820 & \text { if } 122000<x \leq 195000 \\ 0,3 x-26520 & \text { if } 195000<x \leq 270000 \\ 0,35 x-40070 & \text { if } 270000<x \leq 380000 \\ 0,38 x-51470 & \text { if } 380000<x \leq 490000 \\ 0,4 x-61270 & \text { if } 490000<x\end{cases}$

The contextual rule presented as the income tax tables expresses the same information using different conventions (by drawing on contextual language and signifiers). In this study, three tasks were designed to investigate the varying levels of engagement by the teachers with this contextual rule. The first task (Figure 1) required them to calculate the income tax payable for an income of R150 000 in the tax year 2008/2009. The second task (Figure 2) asked the teachers to calculate the income tax using the 2009/2010 tax tables and to then calculate the monthly savings with the new (2009/2010) rates. The third task (Figure 3) asked the teachers what the original income would have been, given an amount of tax that was payable.

\section{Analytic framework used to distinguish between levels of use of the income tax rule}

In studying the contextual attributes of the situation, we identified three demands that need to be attended to in order to use the income tax rule successfully: identifying the 
Task 1

The box below shows the income tax tables for the 2008/2009 tax year.

Information for Task 1

\begin{tabular}{|c|c|}
\hline \multicolumn{2}{|c|}{ Tax rates for individuals: $2008 / 2009$ tax year } \\
\hline Taxable income (R) & Rates of tax \\
\hline $0-122000$ & $18 \%$ of each $\mathrm{R} 1$ \\
\hline $122001-195000$ & R21 $960+25 \%$ of the amount above R122 000 \\
\hline $195001-270000$ & R40 $210+30 \%$ of the amount above R195 000 \\
\hline $270001-380000$ & R67 $710+35 \%$ of the amount above $R 270000$ \\
\hline $380001-490000$ & R101 $210+38 \%$ of the amount above R380 000 \\
\hline 490001 and above & $\mathrm{R} 143010+40 \%$ of the amount above $\mathrm{R} 490000$ \\
\hline \multicolumn{2}{|l|}{ Rebates of tax } \\
\hline \multicolumn{2}{|c|}{ Primary R8280 } \\
\hline
\end{tabular}

Suppose that as a taxpayer, you earned R75 000. To work out the tax that is payable you work out the following:

- Step 1: $18 \%$ of R75 $000=$ R13 500 .

- Step 2: You subtract the primary rebate: R13 $500-$ R8280 $=\mathrm{R} 5220$

- Step 3: So the income tax that is due to be paid by you is R5220, according to the above table.

Question for Task 1: If you earned R150 000 for the year, work out how much tax you would have to pay in total?

Suggested solution to Task 1 :

Amount over $R 122000=R 150000-R 122000=R 28000$

Rate of tax: $\quad=R 21960+25 \%$ of $R 28000$

$=R 28960$

Income tax due $\quad=R 28960-R 8280$

$=R 20680$

FIGURE 1: Details of Task 1, with suggested solution.

appropriate subset (or interval) of the domain within which the income fits, carrying out the routine corresponding to that interval and subtracting the rebate. The first demand involves being able to decode the contextual signifiers 1-132 000 and 132 001-210 000 as denoting the set of values (or interval) within which the input of the rule (income amount) fits. Once the interval is chosen, the routine linked to the interval is also identified. The second challenge is to carry out the appropriate routine to arrive at a numeric answer. This requires the decoding the contextual language used to describe the particular routine; in this case it involves understanding what 'amount above R132 000' meant. Finally, once the routine is completed, it is necessary to recognise that the contextual rule requires a further operation of subtracting the specified primary rebate from the output of the appropriate routine. Linked to this demand is the understanding that for amounts less than R46 000, there will be no tax payable because $18 \%$ of R46 000 is the value of the rebate.

Based on the elaboration of the preceding three demands, we propose four levels of engagement, which we will use as the categories of our analytic framework. These are:

1. No (zero) engagement with the contextual rule: This describes the attempts of a person who does not recognise the role of any of the contextual resources and does not meet any of the demands.

2. Novice engagement with the contextual rule: This describes the attempts of someone who could be meeting
Task 2

Here is the latest tax table for the tax year 2009/2010.

Information for Task 2

\begin{tabular}{|c|c|}
\hline \multicolumn{2}{|c|}{ Tax rates for individuals: $2009 / 2010$ tax year } \\
\hline Taxable income (R) & Rates of tax \\
\hline $0-132000$ & $18 \%$ of each $\mathrm{R} 1$ \\
\hline $132001-210000$ & R23 $760+25 \%$ of the amount above R132 000 \\
\hline $210001-290000$ & R43 $260+30 \%$ of the amount above R210 000 \\
\hline $290001-410000$ & R67 $260+35 \%$ of the amount above R290 000 \\
\hline $410001-525000$ & R109 $260+38 \%$ of the amount above R410 000 \\
\hline 525001 and above & R152 $960+40 \%$ of the amount above R525 000 \\
\hline \multicolumn{2}{|l|}{ Rebates of tax } \\
\hline \multicolumn{2}{|c|}{$\begin{array}{l}\text { Primary R9756 } \\
\text { Addition }\end{array}$} \\
\hline
\end{tabular}

Question for Task 2: Suppose your annual salary is still R150 000. By comparing the tax you would have paid in the previous tax year (2008/2009), to the tax you will pay according to the latest table (2009/2010), work out how much tax you will save per month?

Suggested solution to Task 2:

Income tax due in 2009/2010: Amount over R132000

$=R 150000-R 132000=R 18000$

Rate of tax: $\quad=R 23760+25 \%$ of $R 18000$

$=R 28260$

Income tax due $\quad=R 28260-R 9756$

$=R 18504$

Amount saved $\quad=R 2176$

Amount saved per month $=R 181.33$

FIGURE 2: Details of Task 2, with suggested solution.

\section{Task 3}

Question for Task 3: My friend said that he will pay R125 000 in taxes for the current tax year (2009/2010). What is his annual income?

\begin{tabular}{|c|c|}
\hline Suggested contextual - focused solution: & Algebraic solution: \\
\hline Income tax due $=R 125000$ & Suppose that the amount of \\
\hline Income tax before rebate & his salary above $R 410000$ is $S$. \\
\hline $\begin{array}{l}=R 125000+R 9756 \\
=R 134756\end{array}$ & So $R 109260+38 \%$ of $S=R 134756$ \\
\hline & Thus \\
\hline From the tax table, we can see that & $38 \times S=R 134756-R 109260$ \\
\hline his income bracket is 410001 to 525000 & $100 \quad=R 25496$ \\
\hline $\begin{array}{l}\text { Hence, } R 109260+38 \% \text { of amount } \\
\text { above } R 410000=R 134756\end{array}$ & \\
\hline $\begin{array}{l}\text { So } 38 \% \text { of amount over } \\
\begin{aligned} R 410000 & =R 134756-R 109260 \\
& =R 25496\end{aligned}\end{array}$ & 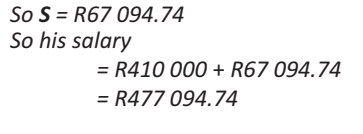 \\
\hline So amount over R410 000 $\begin{aligned} & =R 25496 / 38 \% \\
& =R 67094.74\end{aligned}$ & \\
\hline $\begin{aligned} \text { So his annual salary } & \\
& =R 410000+R 67094.74 \\
& =R 477094.74\end{aligned}$ & \\
\hline
\end{tabular}

FIGURE 3: Details of Task 3, with suggested solutions.

some but not all of the demands embedded in carrying out the contextual rule. Hence, a person operating at the novice level may recognise some but not all the different roles of the contextual resources in completing the routine or rule.

3. Competent engagement with the contextual rule: Competent engagement is demonstrated when a person is able to understand and identify the roles of all the contextual resources and is able to consistently carry out the income tax rule fluently and reliably, in the form in 
which it is presented. Such a person can be described as operating at a competent level.

4. Advanced engagement with the contextual rule: Engagement at the advanced level is demonstrated when a competent user demonstrates a higher or more sophisticated use of the contextual rule. This could be in a situation when the rule may have to be carried out in a different manner than the way it is presented, when the input is an unknown, when the direction of the rule changes, when one is asked questions about properties of the contextual resources involved or when one is asked to find something other than the output of the rule. It may involve manipulating the rule or performing further transformations on the rule so that it is used in a different manner than just computing the result for a given input. It may also involve comparing two rules to make an insightful judgement. At this level, the person should be able to recognise the two representations (symbolic and the table) of the contextual rule as equivalent and to derive similar algebraic representation for related rules

\section{Results}

The results are reported here under the categories zero, novice, competent and advanced levels. We present an example of a response that was categorised under a particular level. Where possible, we also include excerpts from interviews to clarify, or to provide further insight into, the teachers' reasoning. The teachers' verbal and written responses are reported verbatim without any language editing. The teachers are coded by using a combination of the first three letters of their surnames together with the last three digits of their student number. This was done to preserve anonymity whilst at the same time allowing us to go back to the original scripts, if necessary.

\section{Zero level}

There were three teachers who were placed at this level because they were not able to meet any of the demands enunciated in using the contextual rule across Task 1 and Task 2. These teachers did not seem to make sense of the different steps in the calculation. They carried out calculations but these were not based on the rule.

One student (MAB 914) wrote:

$25 / 100 \times \mathrm{R} 150000=\mathrm{R} 37500$

$\mathrm{R} 37500-\mathrm{R} 21960=\mathrm{R} 15540$

He worked out the tax for the first part of Task 2 in a similar manner:

$30 \%$ of $\mathrm{R} 150000=\mathrm{R} 45000$

R45 000 - R43 260 = R1740

Note that MAB 914 followed the same steps for both the tasks: he first found a percentage of the whole amount and then subtracted the first value given in the description of the particular routine (R21 960 in 2008/2009 and R43 260 in $2009 / 2010)$. He did realise that he did not understand what the phrase $25 \%$ of the amount above R122 000 meant when trying to explain why he calculated $25 \%$ of 150 000. An excerpt from his interview appears below, where $\mathrm{R}$ stands for researcher and $\mathrm{T}$ for teacher (MAB 914):

T: Ok, I thought $150, \ldots 150$ is more than that amount

$\mathrm{R}$ : Is more than which amount?

T: eh 122

$\mathrm{R}$ : Yah, ok, if 150000 is more than 122 000?

T: yes, I must just used $25 \%$

This exchange shows that the teacher interpreted the phrase $25 \%$ of the amount above R122 000 as describing that one should calculate $25 \%$ of any amount over 122000 . He did not recognise the speciality of the rule meaning take $25 \%$ of the difference between the income amount and R122 000 . This is similar to the misunderstanding of learners about the transfer duty rule (Bansilal et al., 2012). However, in addition to his misconception about the phrase, he also did not understand what to do with the fixed amount of R21 960, which he subtracted from the result of his first step. A further problem was that for Task 2, MAB 914 used the third option instead of the second one. In fact MAB 914 said 'I even raise my hands to make clear for me only to find that the time was not enough', revealing that he recognised that he did not understand the instruction and raised his hands for help from his tutor but the time was up for the test. MAB 914 attributed some of his difficulties to the fact that he was a specialist physical science teacher (who was retraining to become an ML teacher) and when he came across contexts that were related to science, he had no difficulties. However, he felt that the specialist language used in the tax task was more suited to 'business study BE' or ' economics' people, and was different from the physical science he was used to. He expressed this by saying:

Some of the terminology it was the first time to come across, sometime I too lost somewhere there. ... It is just my first time to come across it at tertiary in fact it contradicts the physics, the physical science. ... I am a science teacher, eh, those who are doing the financials is something that belong to the other subject.

His comments show that he viewed these subjects as being in different domains.

\section{Novice level}

We classified the responses of 20 teachers as being indicative of novice engagement. These teachers demonstrate greater understanding of the stepwise rule because they have successfully met some, but not all, of the demands, unlike the three teachers from the first category who were unable to meet any of the demands embedded in the contextual rule.

Seven teachers chose an irrelevant option, of whom four mimicked the worked example provided at the beginning of the question, showing that they did not meet the first demand, arising from the piecewise nature of the rule. In mathematics 


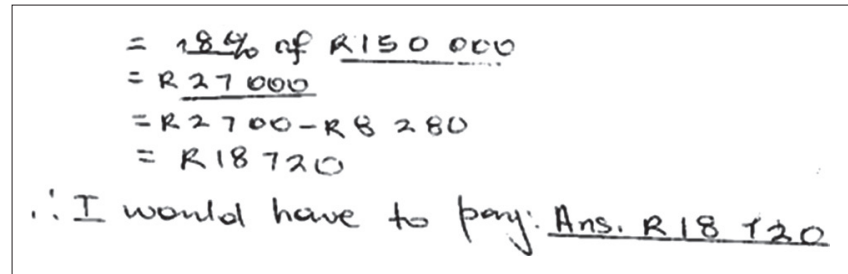

FIGURE 4: Response of KON 486 to Task 1.

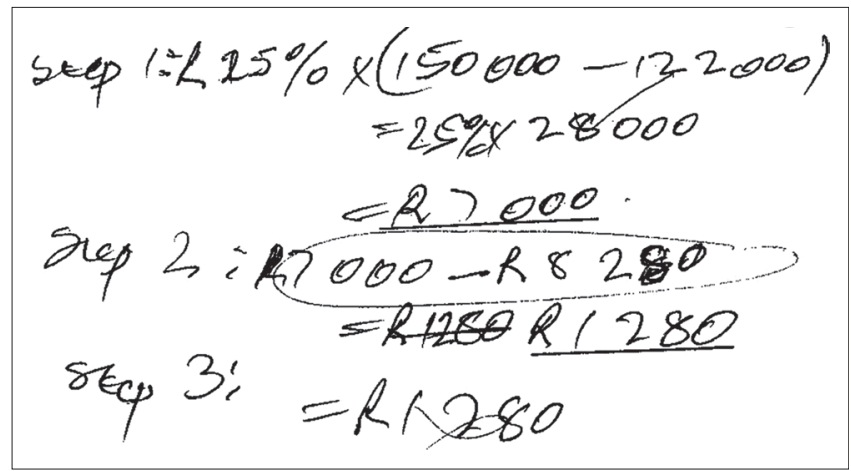

FIGURE 5: Response of MHL 630 to Task 1.

a function is described as piecewise when the domain (values of the independent variable) is broken down into 'pieces' or subsets and each set is governed by a different formula (Luthuli, 2000), as in this case. These participants chose the wrong option; however, they met the demand of subtracting the rebate from the output of the routine associated with the incorrectly chosen option.

The four teachers responded similarly to KON 486, whose response appears in Figure 4.

There were 17 teachers who chose the correct option but erred in other ways. For example, MHL 630 chose the correct option, but did not complete the routine

In Figure 5 we can see that the teacher identified the second option in the rule correctly, but he did not complete the routine correctly, because he did not add in the amount of R21 960. His interview comments suggest that his approach could have been cued by the worked example, which did not require the addition of a fixed amount. Furthermore, MHL 630 subtracted R8280 from the smaller amount of R7000 to get R1280. Perhaps this inconsistent result led to him only doing the first step in Task 2 of subtracting R132 000 from R150 000 and then stopping.

MHL 630 explained that although he had encountered tasks based on income tax calculations in class, he did not spend enough time working on the examples. When asked why he responded as shown, he explained in a disinterested manner: 'I primarily did, yah, I'm not sure, maybe I was following this eh this pattern', referring to the example preceding question 1. However, he felt that the reason for 'messing things up' was because he did not have enough time to study:

I should get enough time, eh? Put myself to eliminate some commitment, other commitment, family, as you said when we beginning this course all those stuff because they've cause disturbances.

In this last statement he was referring to the orientation talk in which the module coordinator pointed out that this 16-credit module required a commitment of 160 notional hours of study. MHL 630 admitted he did not put in the recommended time to study the content.

Eight of the teachers who were categorised in this level had problems understanding the context-specific phrase '25\% of the amount above R122 000'.

These eight teachers produced responses similar to the following:

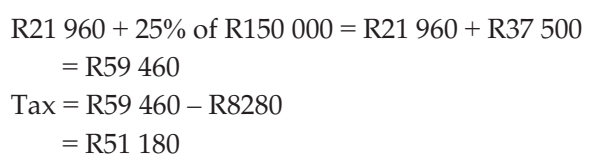

Here these teachers carried out all the steps in the routine. Their only problem was the misconception of the meaning of ' $25 \%$ of the amount above R122 000'. They misinterpreted it as just a description of when the rule was to be applied (on amounts above R122 000) instead of recognising the speciality of the use in the context. This misinterpretation was also identified in the response of MAB 914 (on the zero level) who explained his misconception in his interview.

Another participant who misinterpreted the rule but carried out all the other steps correctly was NDL 627 who wrote $25 \%$ of R122 000 instead of 25\% of (R150 000 - R122 000).

A further two participants on this level carried out all the steps correctly except that they did not subtract the rebate amount at the end.

The teachers operating on this level may need some more practice in recognising the role of the various contextual attributes. Perhaps if the speciality of the contextual language is emphasised, they may improve their competence in performing the contextual rule.

\section{Competent level}

Weclassified the responses of 12 participants as demonstrating competence in executing the contextual rule accurately. These were the teachers who were able to correctly calculate the tax that was due in the two years for the R150 000, thus demonstrating fluency in the use of the rule, but they were unable to produce a solution to Task 3 , which required a more sophisticated use of the rule.

Of these 12 teachers, six worked out the answers to Task 1 and Task 2 completely correctly, but did not obtain the correct answer to Task 3.

There were two teachers who calculated the two tax amounts due for the years 2008/2009 and 2009/2010 correctly, went 


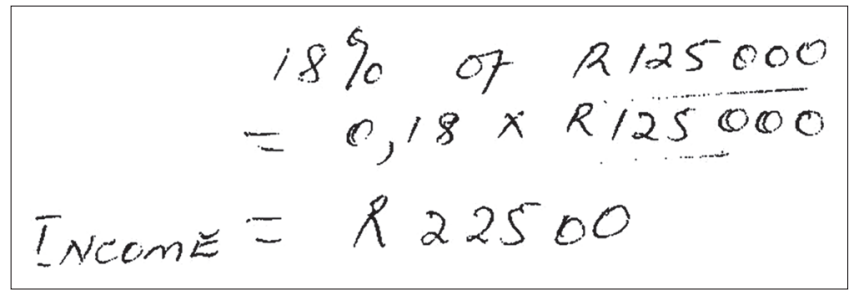

FIGURE 6: Response of ZON 090 to Task 3.

on to find the difference but did not calculate the monthly savings due. In this study, what is under the microscope is their use of the income tax rule, which they have been able to use correctly in two situations and which we took as evidence of their competence. There were a further two teachers who did not find the difference or the projected monthly savings. Again for the same reason cited above, their responses were categorised as indicative of operating on a competent level.

There were two other participants who made minor errors in one question and not the other question who were classified in this category as well. For example, MAD 282 found $25 \%$ of the difference between R180 000 and R122 000 instead of the difference between R150 000 and R122 000, but her calculation for the year 2009/2010 was completely correct. A second person, MAD 301, calculated the sum of R21 $960+$ R7000 as R28 000 instead of R28 960. She did not make a similar error for the second calculation of the income tax due for 2009/2010, so her response was also taken as indicative of operating on a competent level.

\section{Advanced level}

For Task 3, the output of the rule (income tax amount) was given and the teachers were required to calculate the input or the income that could have resulted in the given output. There were two teachers who were able to answer Task 3 correctly, demonstrating their advanced skills in operating the contextual rule. These teachers were able to successfully recognise the inverse nature of the task and to set up an appropriate equation, which took the reverse of each of the steps into consideration, and finally to solved the equation correctly.

There were 19 teachers who did not recognise the inverse nature of the question, which required a reversal strategy. ZON 090 was one of these teachers and her response appears in Figure 6.

Fortunately, she was one of the people who was interviewed, which helped provide insight into why she chose the strategy that she did. When asked by the researcher why she wrote $18 \%$ of R125 000, she replied: '[B]ecause the income between 0 and R132 000 is $18 \%$ of that and I used that ... to calculate.' Here she was trying to explain that 125000 belonged to the interval 0-132 000, which was why she applied the routine pertaining to the first option. The researcher then read the question again to clarify that the R125 000 was the tax and the question asked for the annual income. ZON 090 then said 'I could not calculate the annual income because we were not taught how to calculate it.' Her response suggests that she did not have the algebraic skill to transform the rule to facilitate the calculation of the income (input) given the tax (output) that was payable. The rule when used in the current form takes the input of income and calculates the output of tax payable. ZON 090 has made it clear that she expected a different formula that could be used to do the calculation for Task 3 and was unable to see the rule in the different way required. However, she was able to use the rule in a direct manner in order to arrive at a value for Task 1 and Task 2 . In the case of ZON 090, using the rule to find something other than the output is not feasible, because of her restricted view of the contextual rule.

There were 10 teachers who recognised that the question required a reversal strategy, but they set up an incorrect equation to go about solving it. MAD 301 was one of those who tried a few approaches. He first wrote:

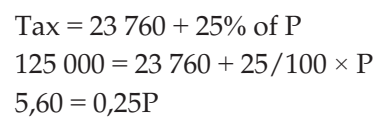

Getting nowhere with this approach, (note his algebraic error of dividing 125000 by 23760 instead of subtracting), he then tried again:

$$
\text { Tax }=152960+40 \% \text { of }(P+525000)
$$

However, he did not make further progress. In his interview he said Task 3 was a problem for him. When asked why, he replied:

To pay R125 000 tax, it goes back to that, it's a reversal thing. ... Looking at the tax he or she paid R125 000 I think I was just try ... here I was not sure I definitely was not sure so for me it still a problem to reverse back.

His comments show (unlike ZON 090) that he recognised the different nature of the question, but he found it difficult to solve. Whereas ZON 090 did not recognise that the solution required a reversal strategy of the same rule, MAD 301 did.

There were also three teachers who did not take the rebate into account before setting up the equation. An example of this is MAD 282 whose response appears in Figure 7.

There were six teachers who recognised the inverse nature of the question and tried to solve the problem by systematically reversing or undoing each step. However, none was able to reach the correct amount. An example illustrating this by MEW 713 appears in Figure 8.

The response by MEW 713 shows that she erred by not reversing the rebate step. She first subtracted R109 260 from R125 000 (top right). She then divided by 38\%, obtaining the amount R41 421, which she added to R410 000 (although her use of the equal sign was not correct). She was able to mentally undo each of the steps in the contextual rule, but she struggled to express it in correct mathematical terms. For example, she took the equal sign as if it meant 'results in' 


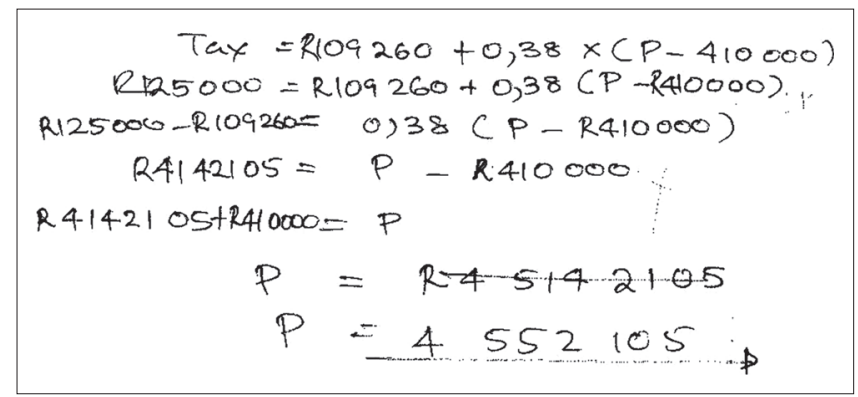

FIGURE 7: Response of participant MAD 282 to Task 3.

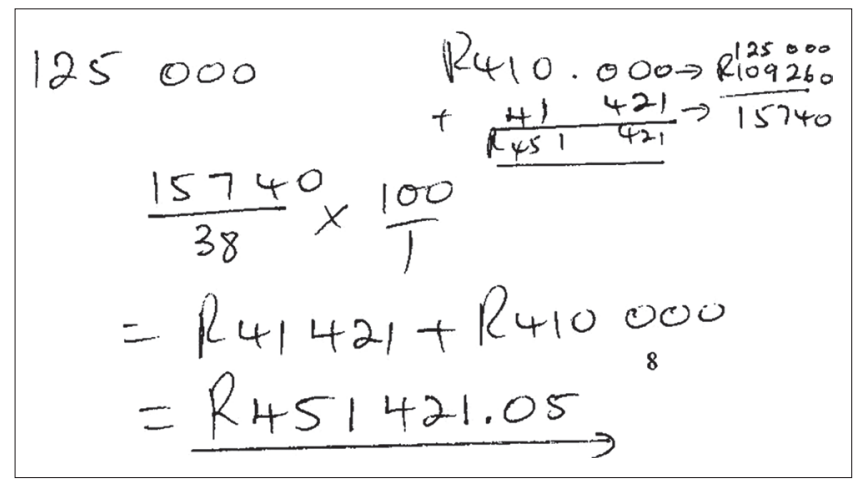

FIGURE 8: Response of MEW 713 to Task 3.

instead of taking it as a mathematical symbol that expresses equality between two sides of an equation. Thus it seems as if she wrote $(15740 / 38) \times 100$ 'results in' 41421 , then adding R410 000, 'results in' R451 421.05. This is a common misconception of the equal sign that is often displayed by beginner algebra students (Kieran, 1992). However, the participant's (MEW 713) steps in undoing the operation at each stage were almost correct except at the beginning where she should have initially added back the rebate, before proceeding further.

\section{Discussion}

The results show that for this small sample of teachers, there is a range of levels of engagement with the income tax rule. The results can be demonstrated graphically, as shown in Figure 9.

Figure 9 illustrates that most teachers (20) were in the novice category, showing that they need assistance in meeting all the demands embedded in the income tax rule. They have demonstrated that they can take account of some, but have ignored others. The most common issue was the misunderstanding of the phrase ' $25 \%$ of the amount above R122 000 '; thus, interventions must help them identify the speciality of the contextual language in this situation. The phrase has two purposes: firstly, it signals when the routine should be applied (on amounts above R122 000) and secondly it details how the routine should be carried out (take $25 \%$ of [the income amount - R122 000]). Most errors in this category originated from taking account of the first purpose only, and not the second. The other obstacle faced by seven teachers was not being able to identify the correct option. In this case, it may help to present these teachers with various income

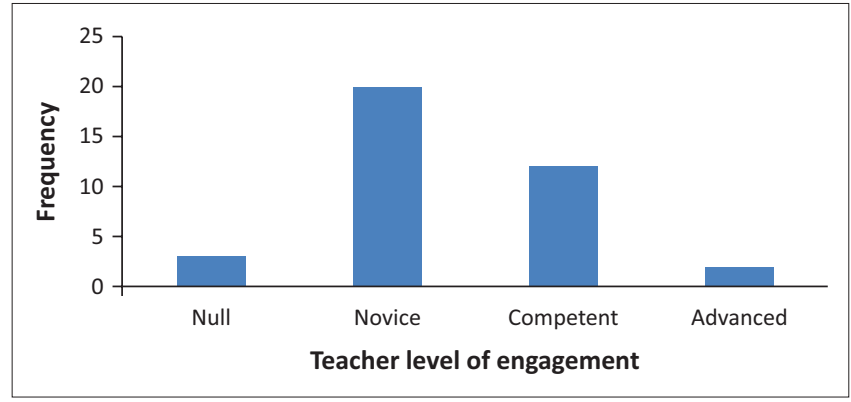

FIGURE 9: Frequency of responses in each category.

amounts and ask them to identify the relevant option in each case. This practice would bring to their notice the role played by the signifiers ' $1-132000$ ', ' $132001-210000$ ', et cetera, as alerting them to the set of values (or interval) within which the income amount falls.

The teachers with zero engagement skills require much more assistance. Perhaps they would benefit from instruction revolving around a simplified or cleaned context, in which the number of intervals or subsets of the domain is reduced, so that they can first pay attention to carrying out the contextual rule in a simpler context. It is evident that they cannot deal simultaneously with all the demands of the income tax rule in its 'uncleaned' form, so they need help in getting rid of some of the noise so that they can understand the rule in simpler situations first.

The 12 teachers performing at the competent level need to be convinced that a rule can be used for other functions besides getting an answer for a given input. The calculation of the income tax can be described by an algorithm and levels of engagement with the algorithm can be understood by drawing upon Usiskin's (2012) elaboration of the five dimensions of understanding, two of which are pertinent in this study. Usiskin emphasises that there are different aspects or dimensions of understanding, which are brought into play in different situations. Those teachers who are on a competent level can be described as demonstrating a skill- algorithmic understanding, which involves application of an algorithm. Usiskin elaborates that a person exhibits a skill-algorithm understanding of a concept when they can complete the algorithm and get the right answer. A person exhibits a higher form of this same type of understanding when they know many ways of getting the right answer (that is, they know different algorithms) and choose a particular algorithm because it is more efficient than others (Usiskin, 2012).

Teachers operating at the advanced level of engagement in our framework can be seen as displaying an understanding similar to what Usiskin (2012) describes as property-proof understanding of a concept, which is understanding that involves justification of mathematical properties that underpin mathematical procedures and relationships:

For many people, understanding has a completely different meaning than obtaining the correct answer in an efficient manner. You don't really understand something unless you can identify the mathematical properties that underlie why your way 
of obtaining the answer worked. 'Understanding' is contrasted with 'doing'. (Usiskin, 2012, p. 508)

Teachers who were able to work at the advanced level exhibited an understanding of the algebra behind the rule and how it was possible to manipulate the given form in order to work out the input amount, showing that they understood the algebraic properties of the income tax rule. Those who recognised the inverse nature of the question in the third task but were unable to model the situation using an equation may benefit from working with similar situations using other rules.

It is worthwhile to note that the teachers could have solved Task 3 by using a systematic reversal strategy which involves 'undoing' each step of the rule, without having to set up an algebraic equation. There were six teachers who attempted this strategy; however, none was successful. Perhaps they may have coped better with such a strategy if the contextual rule was simpler.

\section{Concluding remarks}

In this article we took a real-life scenario (income tax) and designed questions around it for teachers of ML who were enrolled at an in-service course. One of the aims of ML is to promote informed decision-making in real-life situations by using mathematical skills to recognise, interpret and use the contextual resources appropriately. In this case we considered the case of the income tax rule and we investigated four levels of engagement with the rule, which were the zero, novice, competent and advanced levels. We found that most of the teachers were not competent at carrying out the rule because they did not attend to all the demands embedded in the contextual rule. Less than half the group were able to use the contextual rule to compute the income tax payable for particular incomes. Although the third task is not one that is commonly encountered in everyday situations, it has value in a situation when a person may want to estimate the income of somebody who claims to pay such tax. In such a situation, algebra offers additional tools to reach a vantage point. However, all except two ML teachers provided evidence of the algebraic skills required to set up a correct equation to model the situation. Although Task 3 could have been solved by a reversal strategy, few teachers chose that route. This illustrates that the interpretation and use of some contextual rules may require sophisticated mathematical skills. ML teachers require more than just a skill-algorithmic understanding of a rule that they will be teaching their learners. In order to deal with complex applications, a property-proof understanding of the rule may serve them better as teachers (Usiskin, 2012). However, in this group, there were only two teachers whose algebraic skills displayed in their responses could be indicative of such an understanding.

Another issue that emerges in questions set around real-life contexts is that of working within and across domains. In this study it emerged that the contextual language posed a barrier to many teachers. By not being able to decode the contextual language, they did not access the specific information directing them to when and how the routine could be executed. The implications are thus that there are two domains of engagement that intersect and one has to learn the rules of engagement of each in order to progress and to consider the more challenging questions.

A limitation of the study is that the study is set within a classroom setting. We acknowledge that understanding how people engage with contextual rules in their everyday situation is a complex task and that there is a substantial difference between a real-life situation as actually experienced and one that is recontextualised into a textual representation used in a classroom teaching or assessment activity. However, this study contributes to knowledge about the use of ML assessments based on real-life contexts. We hope that by analysing the responses of teachers to these tasks set around the particular contextual rule for income tax, we have elaborated on some of the demands associated with ML tasks. Lessons learnt from this particular example of a contextual rule based on a piecewise function could be extended to other similar contextual rules such as municipal tariffs, transfer duty taxes, etc. We hope that other researchers are motivated to study engagement with similar contextual rules, in a classroom or in a real-life situation, in order to extend our findings or to refute them.

\section{Acknowledgements}

The authors would like to thank Mr E. Masondo for his help in conducting the interviews.

\section{Competing interests}

The authors declare that they have no financial or personal relationship(s) that may have inappropriately influenced them in writing this article.

\section{Authors' contributions}

S.B. (University of KwaZulu-Natal) was the project leader. The data collection was supervised by both S.B. and T.W.M. (University of KwaZulu-Natal). The data analysis and writeup was done by both authors.

\section{References}

Bansilal, S. (2011). Unpacking Mathematical Literacy teachers' understanding of the concept of inflation. African Journal for Research in Science, Mathematics and Technology Education, 15(2), 179-190. Available from http://hdl.handle. and Technology Education $15(2)$, $179-190$. Available from http://hdl.handle. /EJC92749

Bansilal, S. (2013). Understanding the contextual resources necessary for engaging in Mathematical Literacy assessment tasks. Journal of Education, 58, 1-22. Available from http://joe.ukzn.ac.za/Libraries/No_58_2013/joe_58_bansilal.sflb.ashx

Bansilal, S., \& Debba, R (2012). The role of contextual attributes in learners' responses to a Mathematical Literacy assessment task. African Journal for Research in Science, Mathematics and Technology Education, 16(3), 302-316. Available from http://hdl.handle.net/10520/EJC127153

Bansilal, S., Mkhwanazi, T.W., \& Mahlabela, P. (2012). Mathematical Literacy teachers' engagement with contextual tasks based on personal finance. Perspectives in Education, 30(3), 98-109. Available from http://hdl.handle.net/10520/EJC125392

Botha, J.J. (2011). Exploring mathematical literacy: The relationship between teachers' knowledge and beliefs and their instructional practices. Unpublished doctoral dissertation. Faculty of Science, University of Pretoria, Pretoria.

Denzin, N.K., \& Lincoln, Y. (2008). Introduction: The discipline and practice of qualitative research. In N.K Denzin, \& Y. Lincoln (Eds.), Strategies of qualitative inquiry (pp. 1-44). Los Angeles, CA: Sage. 
Department of Basic Education. (2011). Curriculum and assessment policy statement. Further education and training phase. Mathematical Literacy. Pretoria: DBE.

Duranti, A., \& Goodwin, C. (1992). Rethinking contexts: Language as an interactive phenomenon. Cambridge: Cambridge University Press.

Gilbert, J. (2006). On the nature of context in chemical education. International Journal of Science Education, 28(9), 957-976. http://dx.doi.org/10.1080/09500690600702470

Greeno, J.G. (1991). Number sense as situated knowing in a conceptual domain Journal for Research in Mathematics Education, 22(3), 170-218. http://dx.doi. org/10.2307/749074

Hechter, J.E. (2011). Analysing and understanding teacher development on mathematical literacy ACE course. Unpublished Master's thesis. University of the Witwatersrand, Johannesburg, South Africa.

Jansen, J. (2011, 23 February). Sinking deeper into mediocrity. The Times, p. 15.

Kieran, C. (1992). The learning and teaching of school algebra. In D.A. Grouws (Ed.), Handbook of research on mathematics teaching and learning (pp. 390-419). New York, NY: Macmillan Publishing Co, Inc.

KwaZulu-Natal Department of Education (2009). Grade 12 KZN Mathematical Literacy Grade 12 trial examination paper 2. Unpublished.

Luthuli D. (2000). Some everyday applications of piecewise functions. Pythagoras, $53,22-27$.
Nel, B.P. (2012). Transformation of teacher identity through a Mathematical Literacy re-skilling programme. South African Journal of Education, 32, 144-154.

Pillay, K.S. (2006). Readiness of learners to study space, shape and measurement in Mathematical Literacy: Case studies at two Durban schools. Unpublished Master's thesis. School of Education, University of KwaZulu-Natal, Durban, South Africa.

Shulman, L. (1986). Those who understand: Knowledge growth in teaching. Educational Researcher, 15(2), 4-14. http://dx.doi.org/10.3102/0013189X015002004

Usiskin, Z. (2012, July). What does it mean to understand some mathematics? Paper presented at the 12th International Congress on Mathematical Education, COEX, Seoul, Korea.

Vale, P. (2012, May). Mathematical Literacy test items and student errors: Investigating linguistic complexity. Paper presented at UMALUSI conference, Muldersdrift, South Africa.

Venkat, H. (2010). Exploring the nature and coherence of mathematical work in South African Mathematical Literacy classrooms. Research in Mathematics Education 12(1), 53-68. http://dx.doi.org/10.1080/14794800903569865

Venkat, H., \& Graven, M. (2008). Opening up spaces for learning: learners' perceptions of mathematical literacy in grade 10. Education as Change, 12(1), 29-44. http://dx.doi.org/10.1080/16823200809487193 